\title{
ANÁLISE DA PRECISÃO NO POSICIONAMENTO COM UM RECEPTOR GPS DE NAVEGAÇÃO
}

\author{
Thiago Cruz Rodrigues Franco, IF Sul de Minas Gerais - Campus Inconfidentes \\ agrimensorthiago@hotmail.com
}

\section{RESUMO}

Este trabalho teve por objetivo o estabelecimento de dados a partir de determinações em campo, na área urbana da cidade de Inconfidentes, Minas Gerais. Foram feitas comparações entre o posicionamento com receptores GPS de navegação e posicionamento com receptores GPS de precisão. Baseando-se nos resultados, ficou claro que receptores GPS de navegação não oferecem precisão suficiente para responder demandas técnicas e legais. Com o objetivo de analisar a precisão no posicionamento com um receptor GPS de navegação, propõe-se: Comparação entre as coordenadas mais prováveis calculadas pelo método estatístico da média ponderada e coordenadas levantadas com antena receptora GPS de precisão; Comparação entre os pontos de cada repetição e pontos levantados com um receptor GPS de precisão.

\section{ABSTRACT}

\section{PRECISION ANALYSIS IN POSITIONING WITH A GPS NAVIGATION RECEIVER}

This work has been aimed in establishing data from determinations in field in a farm owned by the Federal Institute of Education, Science and Technology of South Minas Gerais - Campus Inconfidentes, located at $22^{\circ} 19^{\prime} 16^{\prime \prime} \mathrm{S}$ and $46^{\circ} 18^{\prime} 40^{\prime} \mathrm{W}$. Comparisons were made between navigation GPS and precision geodesic GPS data. Based on the results, the conclusion was that navigation GPS does not offers enough precision to respond legal and technical demands. In order to analyze the positioning precision with a GPS navigation, it is proposed: Comparison between the most probable coordinates calculated by statistical method of the weighted average and coordinates raised with a precision geodesic GPS; Comparison between each repetition of positioning and surveying with a precision geodesic GPS (real coordinates); Comparison between sets of repetitions and their most likely values calculated using the weighted average.

\section{INTRODUÇÃO}

O NAVSTAR-GPS (Navigation Satellite with Time And Ranging - Global Positioning System), mais conhecido como GPS, é um sistema global de posicionamento via rádio, desenvolvido pelo DoD - Departamento de Defesa dos EUA.

O levantamento com receptores GPS de navegação é um tipo de posicionamento dito simples ou absoluto: as coordenadas do ponto são determinadas em tempo real no sistema de referência WGS 84 (World Geodetic System - 1984), independentemente da hora ou das condições climáticas. No posicionamento absoluto o receptor ou antena receptora utiliza a pseudodistância ${ }^{1}$ derivada do código C/A presente na onda portadora L1, emitida pelos satélites da rede GPS (31 ativos atualmete) para determinação das coordenadas. Como forma de garantir a segurança nacional dos EUA, o DoD (Department of Defense) impôs um programa de degradação dos sinais emitidos pelos satélites

\footnotetext{
${ }^{1}$ Segundo MONICO, diz-se pseudodistância em razão do tempo assíncrono entre o relógio do receptor e do satélite.
} 
(chamado de efeito SA - Selective Availability), impossibilitandoníveis melhores de exatidãopara este tipo de posicionamento que apresentava, até o dia 1 de maio de 2000, precisão planimétrica de \pm 100 m e altimétrica de \pm 140 m (Monico, 2007). Após a desativação do $\mathrm{SA}^{2}$, ocorreu uma melhora significativa na acurácia dos posicionamentos para $\pm 10 \mathrm{~m}$ nas coordenadas planimétricas e $\pm 15 \mathrm{~m}$ na altimétrica. Este fato viabilizou argumentos por parte de alguns profissionais equivocados para utilização de receptores GPS de navegação na determinação de pontos de apoio em levantamentos topográficos e até mesmo em levantamentos geodésicos, visto que para uma área relativamente grande o erro no perímetro e área é considerado tolerável para estes profissionais.

Atualmente existem aparelhos (receptores) capazes de uma precisão planimétrica de \pm 2 $\mathrm{m}$. Entretanto, tal precisão de $\pm 2 \mathrm{~m}$ apenas pode ser considerada se para o levantamento for feita uma série de repetições e ao final realizar um tratamento estatístico.

Na realização de trabalhos geodésicos, que exigem alto grau de confiança são necessários métodos de abordagem que possam garantir uma acurácia mínima necessária, tanto no levantamento em campoquantono processamento dos dados, determinando desta forma os valores mais prováveis das medições (coordenadas com precisão mínima exigida em normas de levantamentos topográficos e geodésicos). Em outras palavras, o grau de confiabilidade e o valor mais provável das coordenadas dependem tanto da precisão do aparelho quanto dos erros inerentes ao processo de obtenção posicional. Para antenas receptoras de precisão são utilizados métodos pós-processados, referente ao tipo de levantamento geodésico, garantindo, em alguns casos, precisão milimétrica.

No posicionamento com receptor GPS

\footnotetext{
2 Segundo SEGANTINE, 2005, SA (Selective Availability Disponibilidade Seletiva) é um efeito de degradação do sinal e consequentemente das coordenadas finais do ponto observado. É a manipulação, proposital, dos dados referentes ao tempo de emissão do sinal e/ou das coordenadas dos satélites.
}

de navegação não é possível fazer o pósprocessamento dos dados, uma vez que este tipo de receptor não registra as observáveis pseudodistância (código C/A) e fase da onda portadora L1, chamados de "dados brutos", bem como não há meios de se determinar o centro de fase destes receptores. O receptor de navegação apenas utiliza esses dados para os cálculos das distâncias (pseudodistância), no momento do posicionamento, através da relação existente entre velocidade e tempo:

\section{$D I S T A \hat{A} N C I A=V E L O C I D A D E \cdot T E M P O$}

Basicamente, a distância receptor/satélite é igual à velocidade da onda de rádio vezes o tempo decorrido entre a emissão e recepção desta onda. O receptor realiza cálculos de trilateração e assim determina a posição de um ponto na superfície terrestre.

Contudo, não é possível o posicionamento com precisão e acurácia mínimas almejadas em medições geodésicas, pois os erros são incontroláveis e aleatórios. As medidas possuem diferentes graus de precisão porque sofrem influência do tempo (relógio impreciso do receptor de navegação), do número de satélites e sua geometria, entre outros fatores e, portanto, as coordenadas obtidas não são confiáveis. Isto ocorre porque não há como realizar o pósprocessamento das informações levantadas, bem como dependem das diversas condições intrínsecas ao posicionamento GPS.

\section{Erros nas observações com receptor GPS}

Todo tipo de medição é passível de erros. No caso de observações com receptor GPS, os erros são devidos à:

- Atrasos na ionosfera e troposfera: Os sinais dos satélites diminuem de intensidade à medida que atravessam a atmosfera.

- Sinal com caminhos múltiplos (multicaminhamento): Isto ocorre quando o sinal GPS é refletido por objetos como prédios altos ou 
montanhas, antes de alcançarem o receptor. Isto aumenta o tempo que o sinal leva do satélite até o receptor.

- Erros do relógio do receptor: O relógio interno do receptor não é tão preciso quanto o relógio atômico dos satélites GPS. Relógios de receptores de navegação não são confiáveis como os relógios de receptores geodésicos.

- Erros de órbita: Também conhecidos como erros de efeméride; Os erros de órbita representam erros nas informações das posições dos satélites.

- Número de satélites visíveis: Quanto mais satélites um receptor GPS puder enxergar no céu, melhor é a precisão.

- Geometria dos satélites: Refere-se à posição relativa dos satélites em um dado instante. A geometria ideal dos satélites á alcançada quando estão localizados em grandes ângulos em relação a outros satélites. Uma geometria ruim de satélites ocorre quando estão alinhados em linha reta ou num grupo muito unido. Esta melhor posição ou geometria é fornecida pelo valor DOP.

Segundo Segantine (2005), a precisão fornecida pelo GPS refere-se ao equipamento utilizado no posicionamento de modo a garantir a repetibilidade dos resultados. Uma vez que um receptor de navegação não possui centro de fase determinado é impossível realizar a repetição das medições exatamente nos mesmos pontos. Além do que, como visto anteriormente, existem muitos outros fatores de imprecisão nos resultados obtidos com este tipo de receptor.

Precisão é a consistência da medida ou grau de refinamento de um grupo de medidas, relacionados com a invariabilidade das observações obtidas em condições rigorosamente similares. Nas medições, os termos mais usados para expressar a precisão são a variância e o desvio padrão (erro médio quadrático ou RMS - Root Mean Square) (Silva, 2006).

No caso de posicionamento com receptores GPS, em geral, quanto maior for o número de satélites captados no horizonte da antena receptora, maior será a precisão das coordenadas do ponto medido. Tais antenas receptoras utilizam os melhores conjuntos de quatro satélites no momento da medição para realizar a trilateração e assim obter as coordenadas do ponto. Esta melhor situação é dada pelo valor do DOP que, em conceito, envolve as posições dos satélites em determinado instante (Segantine, 2005). Entretanto, este valor DOP não pode ser gerado a partir de receptores de navegação. Como as posições dos satélites possuem uma geometria inconstante, a precisão mínima para levantamentos geodésicos fica comprometida, além do que, é impossível registrar os "dados brutos" emitidos pelos satélites (código C/A e/ou fase da portadora), impossibilitando os cálculos para uma determinação mais acurada das coordenadas, e conseqüente eliminação de diversos erros envolvidos no posicionamento GPS.

\section{MATERIAL E MÉTODOS}

Nos levantamentos geodésicos as medidas podem ser consideradas como variáveis aleatórias e, portanto, admiti-se um tratamento baseado nas leis da estatística (Silva, 2006).

Para a determinação do valor mais provável de uma medição (coordenadas X, Y, Z), a partir de uma série de observações, com diferentes graus de precisão, a média aritmética não pode ser considerada como valor mais provável, pois é válida apenas para observações com mesmo grau de confiança, ou seja, mesmas condições de obtenção das medidas (Comastri, 1979). No caso de observações com diferentes graus de precisão, o valor mais provável deverá ser obtido considerando-se a variância (variabilidade) de cada observação o que gera um fator de proporcionalidade denominado peso (Silva, 2006). Em outras palavras, para determinação da média de uma série de posicionamentos com um receptor GPS de navegação, visto que existem diversos fatores de variância, torna-se claro a necessidade da introdução de um peso, com a finalidadedetornarestasobservaçõeshomogêneas 
e possibilitando desta forma a determinação do valor mais provável (coordenadas $\mathrm{X}, \mathrm{Y}$, Z) através da média ponderada. Entretanto, mesmo com a aplicação deste método estatístico é necessário dizer que o valor mais provável encontrado não será confiável, visto os diversos fatores que corroboram a não fidedignidade das observações, como a incapacidade de registrar as observáveis pseudodistância (código C/A) e fase da onda portadora L1 emitidos pelos satélites GPS. A aplicação deste método estatístico fornecerá apenas o valor mais provável de uma série de medições realizadas sobre os mesmos pontos, o que, ao final, espera-se encontrar as coordenadas dos pontos mais próximas das reais quanto possível, a depender, é claro, da precisão do receptor. Desta forma, as coordenadas finais encontradas devem apresentar uma proximidade das coordenadas reais relativas à precisão do receptor de navegação. Ao final deste trabalho o que se pretende é mostrar a variabilidade posicional com receptores de navegação e que a precisão garantida pelo receptor apenas é alcançada realizando-se repetições. Com isto, espera-se esclarecer que mesmo com a aplicação de repetições para a obtenção de coordenadas mais precisas, estas apenas comprovam a precisão do receptor de navegação utilizado nos posicionamentos, sendo sua utilização inadmissível para levantamentos geodésicos, pois não fornece garantia alguma de exatidão, uma vez que a precisão das medições é demasiadamente aleatória, sendo na maioria das vezes pior que a prometida pelo fabricante do receptor, dependendo de diversos fatores, citados na seção 2 anterior.

Com objetivo de avaliar a qualidade do posicionamento absoluto com um receptor Garmin GPSmap 60CSx, foi realizado o posicionamento absoluto sobre 4 pontos, materializados na cidade de Inconfidentes - MG (Figura 1), com uma série de 6 repetições em cada ponto, em três dias e horários diferentes, Tabela 1 , visando comprovar que o posicionamento com este tipo de receptores apresenta alto grau de variabilidade nas suas medições. Objetivouse uma análise comparativa da precisão, sobre 4 pontos de referência, materializados, $\mathrm{P} 1, \mathrm{P} 2, \mathrm{P} 3 \mathrm{e}$ $\mathrm{P} 4$, os quais foram previamente levantados com

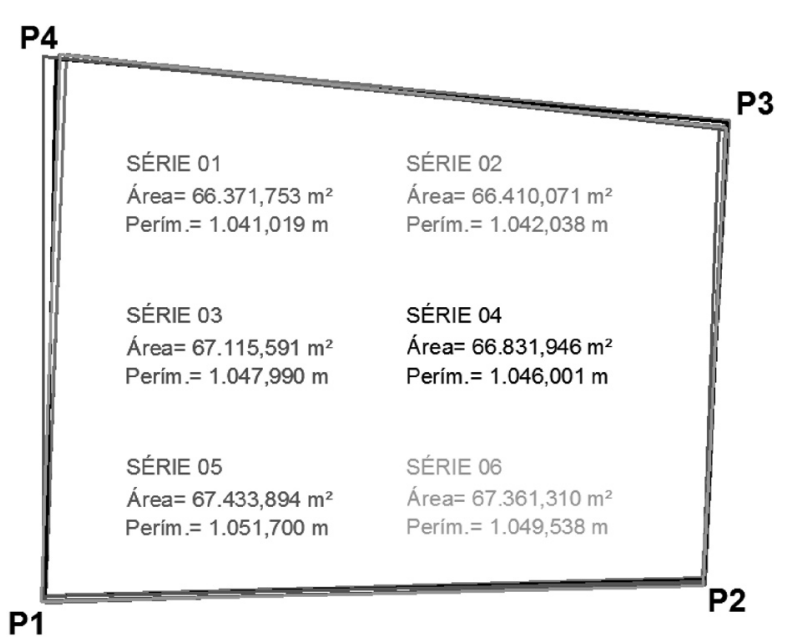

FIGURA 1. Sobreposição das séries de posicionamentos com receptor GPS de navegação na cidade de Inconfidentes/MG.

TABELA1. Tabela de coordenadas UTM SIRGAS2000, com datas, horas, número de satélites e precisão no momento dos posicionamentos.

\begin{tabular}{|c|c|c|c|c|c|c|}
\hline \multirow{2}{*}{ Séries } & \multicolumn{3}{|c|}{ COORDENADAS UTM } & \multirow{2}{*}{ Data - Hora } & \multirow{2}{*}{ Satélites } & \multirow{2}{*}{ Precisão } \\
\hline & $\mathbf{E}(\mathbf{m})$ & $\mathbf{N}(\mathbf{m})$ & $\mathbf{Z}(\mathbf{m})$ & & & \\
\hline Thi01 & $363.109,786$ & $7.531 .201,554$ & 893,665 & $10 / 09 / 200915: 25$ & 9 & 3 \\
\hline Thi02 & $363.399,579$ & $7.531 .145,035$ & 903,037 & $10 / 09 / 200915: 30$ & 9 & 3 \\
\hline Thi03 & $363.451,605$ & $7.531 .343,277$ & 883,090 & 10/09/2009 15:36 & 9 & 3 \\
\hline Thi04 & $363.173,399$ & $7.531 .439,602$ & 874,438 & 10/09/2009 16:39 & 9 & 3 \\
\hline Thi05 & $363.110,328$ & $7.531 .204,659$ & 891,502 & $10 / 09 / 200920: 32$ & 9 & 3 \\
\hline Thi06 & $363.399,482$ & $7.531 .147,299$ & 900,634 & $10 / 09 / 200920: 37$ & 10 & 3 \\
\hline Thi07 & $363.456,901$ & $7.531 .344,874$ & 880,206 & 10/09/2009 20:41 & 10 & 3 \\
\hline Thi08 & $363.173,335$ & $7.531 .439,044$ & 871,554 & 10/09/2009 20:45 & 10 & 3 \\
\hline Thi09 & $363.108,664$ & $7.531 .202,472$ & 891,502 & 11/09/2009 12:29 & 12 & 2 \\
\hline Thi10 & $363.400,082$ & $7.531 .143,824$ & 901,115 & 11/09/2009 12:35 & 12 & 2 \\
\hline Thi11 & $363.453,982$ & $7.531 .340,987$ & 881,648 & 11/09/2009 12:41 & 12 & 2 \\
\hline Thi12 & $363.170,353$ & $7.531 .440,392$ & 873,237 & 11/09/2009 12:47 & 12 & 2 \\
\hline Thi13 & $363.110,245$ & $7.531 .204,278$ & 892,223 & $11 / 09 / 200917: 05$ & 11 & 3 \\
\hline Thi14 & $363.400,306$ & $7.531 .145,877$ & 901,836 & 11/09/2009 17:10 & 11 & 3 \\
\hline Thi15 & $363.455,992$ & $7.531 .344,225$ & 882,129 & 11/09/2009 17:16 & 11 & 3 \\
\hline Thi16 & $363.168,443$ & $7.531 .438,621$ & 872,275 & $11 / 09 / 200917: 22$ & 11 & 3 \\
\hline Thi17 & $363.109,208$ & $7.531 .204,435$ & 874,679 & 11/09/2009 22:17 & 9 & 3 \\
\hline Thi18 & $363.399,604$ & $7.531 .145,128$ & 887,657 & $11 / 09 / 200922: 23$ & 9 & 3 \\
\hline Thi19 & $363.454,426$ & $7.531 .342,550$ & 867,950 & $11 / 09 / 200922: 28$ & 9 & 3 \\
\hline Thi20 & $363.162,886$ & $7.531 .441,096$ & 865,546 & $11 / 09 / 200922: 35$ & 9 & 3 \\
\hline Thi21 & $363.108,078$ & $7.531 .202,356$ & 889,819 & $12 / 09 / 200908: 58$ & 11 & 3 \\
\hline Thi22 & $363.399,350$ & $7.531 .143,604$ & 901,355 & 12/09/2009 09:03 & 11 & 3 \\
\hline Thi23 & $363.454,596$ & $7.531 .341,856$ & 880,927 & $12 / 09 / 200909: 10$ & 11 & 3 \\
\hline Thi24 & $363.170,639$ & $7.531 .440,320$ & 871,074 & $12 / 09 / 200909: 16$ & 10 & 2 \\
\hline \multicolumn{7}{|c|}{ LEVANTAMENTO DE REFERÊNCIA } \\
\hline Pontos & $\mathbf{E}(\mathbf{m})$ & $\mathbf{N}(\mathbf{m})$ & $\mathrm{Z}(\mathrm{m})$ & \multirow{5}{*}{\multicolumn{3}{|c|}{$\begin{array}{l}\text { Data: } 28 / 05 / 2009 \\
\text { GNSS Leica } 900 \mathrm{C} / \mathrm{S}-\mathrm{L} 1 / \mathrm{L} 2 \\
\text { Utilizou-se como referência a estação de } \\
\text { monitoramento contínuo MGIN de } \\
\text { Inconfidentes - MG. }\end{array}$}} \\
\hline P1 & $363.108,401$ & $7.531 .202,072$ & 886,512 & & & \\
\hline P2 & $363.170,905$ & $7.531 .438,682$ & 866,469 & & & \\
\hline P3 & $363.453,855$ & $7.531 .340,724$ & 876,305 & & & \\
\hline P4 & $363.398,917$ & $7.531 .143,943$ & 897,201 & & & \\
\hline
\end{tabular}




\section{Média ponderada: valor mais provável dos parâmetros $\mathbf{E}, \mathbf{N}$ e Z .}

Para a determinação do valor mais provável das observações, com diferentes graus de precisão, considera-se a variância de cada observação, o que gera um fator de proporcionalidade denominado peso (Silva, 2006). Desta forma, o valor mais provável a ser encontrado é determinado através da média ponderada de cada parâmetro, isoladamente.

Com o cálculo das médias ponderadas é possível determinar o erro médio quadrático, em função dos erros aparentes e assim evidenciar a variância das observações, neste caso, variância dos parâmetros altimétricos e planimétricos.

As observações realizadas com receptor GPS de navegação são três parâmetros $(\mathrm{E}, \mathrm{N}$, $\mathrm{Z})$ que determinam a posição de um ponto, em função do número de satélites.

As precisões indicadas pelo receptor variaram de \pm 2 a \pm 3 metros e relacionamse com número de satélites e sua geometria, calculadas pelo receptor, no momento da aquisição posicional.

Visando a determinação dos valores mais prováveis dos parâmetros em função da precisão e número de satélites no momento do posicionamento, os pesos, fatores $\mathrm{Pe} \mathrm{S}$, foram determinados conforme abaixo:

Para 09 Satélites: fator $\mathrm{S}=1$;

Para Precisão de \pm 2 : fator $\mathrm{P}=1,5$

Para 10 Satélites: fator $\mathrm{S}=2$;

Para Precisão de \pm 3 : fator $\mathrm{P}=0,5$

Para 11 Satélites: fator $\mathrm{S}=3$;

Para 12 Satélites: fator $\mathrm{S}=4$;

A Tabela 2 mostra os fatores $\mathrm{S}$ e $\mathrm{P}$, correlacionados com os pontos e séries de repetições, satélites e precisão no momento da aquisição posicional, o que gerou um peso final que é o somatório dos fatores $\mathrm{S}$ e $\mathrm{P}$ de proporcionalidade.
TABELA 2. Tabela de fatores de proporcionalidade em função da precisão fornecida pelo receptor e do número de satélites no momento da aquisição posicional.

\begin{tabular}{|c|c|c|c|c|c|c|}
\hline Pontos & Séries & Satélites & Precisão & Fator S & Fator $\mathbf{P}$ & PESO \\
\hline \multirow{6}{*}{$\mathrm{P} 1$} & Thi2 & 9 & 3 & 1 & 0,5 & 1,500 \\
\hline & Thi10 & 9 & 3 & 1 & 0,5 & 1,500 \\
\hline & Thi18 & 12 & 2 & 4 & 1,5 & 5,500 \\
\hline & Thi26 & 11 & 3 & 3 & 0,5 & 3,500 \\
\hline & Thi34 & 9 & 3 & 1 & 0,5 & 1,500 \\
\hline & Thi42 & 11 & 3 & 3 & 0,5 & 3,500 \\
\hline \multirow{6}{*}{$\mathrm{P} 2$} & Thi3 & 9 & 3 & 1 & 0,5 & 1,500 \\
\hline & Thi11 & 10 & 3 & 2 & 0,5 & 2,500 \\
\hline & Thi19 & 12 & 2 & 4 & 1,5 & 5,500 \\
\hline & Thi27 & 11 & 3 & 3 & 0,5 & 3,500 \\
\hline & Thi35 & 9 & 3 & 1 & 0,5 & 1,500 \\
\hline & Thi43 & 11 & 3 & 3 & 0,5 & 3,500 \\
\hline \multirow{6}{*}{ P3 } & Thi4 & 9 & 3 & 1 & 0,5 & 1,500 \\
\hline & Thi12 & 10 & 3 & 2 & 0,5 & 2,500 \\
\hline & Thi20 & 12 & 2 & 4 & 1,5 & 5,500 \\
\hline & Thi28 & 11 & 3 & 3 & 0,5 & 3,500 \\
\hline & Thi36 & 9 & 3 & 1 & 0,5 & 1,500 \\
\hline & Thi44 & 11 & 3 & 3 & 0,5 & 3,500 \\
\hline \multirow{6}{*}{$\mathrm{P} 4$} & Thi8 & 9 & 3 & 1 & 0,5 & 1,500 \\
\hline & Thi16 & 10 & 3 & 2 & 0,5 & 2,500 \\
\hline & Thi24 & 12 & 2 & 4 & 1,5 & 5,500 \\
\hline & Thi32 & 11 & 3 & 3 & 0,5 & 3,500 \\
\hline & Thi40 & 9 & 3 & 1 & 0,5 & 1,500 \\
\hline & Thi48 & 10 & 2 & 2 & 1,5 & 3,500 \\
\hline
\end{tabular}

Uma vez que foram determinados os pesos em função do número de satélites e da precisão do receptor, no momento dos posicionamentos, foi feito o cálculo da média ponderada. Entretanto, a média ponderada, por si só, não é o valor mais provável, uma vez que esta média correlaciona-se diretamente com um desvio padrão. Este desvio, por sua vez correlaciona-se diretamente com um fator de proporcionalidade das medições com diferentes graus de precisão, o peso. Assim, o valor mais provável dos parâmetros observados será a média ponderada mais ou menos um desvio padrão da média das séries de observações. $\mathrm{O}$ desvio padrão da média está relacionado com a precisão obtida no cálculo da média ponderada em função de cada série de 6 repetições nos 4 pontos e depende diretamente do peso atribuído no cálculo. Em outras palavras, a média ponderada não sofre influência do peso, pela equação 2, mais adiante. Entretanto, o desvio padrão da média sofrerá influência do peso em função da equação 4 , adiante.

Para os cálculos foi utilizado o Microsoft 
Excel2007 eas séries de repetições foram ordenadas de acordo com os pontos P1, P2, P3 e P4.

Para determinação dos valores mais prováveis das coordenadas, aqui chamadas de parâmetros $\mathrm{E}, \mathrm{N}$ e Z, primeiro é necessário determinar a média ponderada, depois o resíduo, então o erro médio quadrático ou desvio padrão " $\sigma$ ", para en guida calcular o desvio padrão da média " $\sigma_{\overline{\mathrm{x}}_{\mathrm{P}}}$ " das séries de repetições em cada ponto.

Assim, para o cálculo dos valores mais prováveis de cada parâmetro, Tabela 7 , foi utilizada a equação 1 , abaixo:

\section{Valor mais provável $=\bar{x}_{P} \pm \sigma_{\overline{\mathrm{x}}_{\mathrm{P}}}$}

Onde,

$$
\bar{x}_{p}=\text { média ponderada; }
$$

$$
\sigma_{\bar{x}_{P}}=\text { desvio padrão da média; }
$$

Uma vez que se obtiveram os fatores de proporcionalidade, Tabela 2, para cada parâmetro, tornou-se possível o cálculo da média ponderada:

As médias ponderadas da Tabela 3 foram calculadas pela equação 2 abaixo.

$$
\bar{x}_{P}=\frac{\sum_{i=1}^{n}\left(\bar{x} \cdot P_{i}\right)}{\sum_{i=1}^{n} P_{i}}
$$

Onde,

$\overline{\mathrm{x}}_{\mathrm{p}}=$ média ponderada;

$\overline{\mathrm{x}}=$ média das observações em cada ponto;

$P_{i}=$ peso atribuído a cada observação;

Entretanto, somente a média ponderada não pode ser considerada como valor mais provável, uma vez que estes dependem do fator de proporcionalidade (peso). Logo, são valores com diferentes graus de precisão que, em função do método estatístico adotado, possuem, intrinsecamente, um desvio padrão da média, correlacionado a cada série de repetições.

Assim, para calcular o desvio padrão da média, através do desvio padrão das observações é necessário calcular o resíduo ou erro aparente "e", pela equação 3 abaixo. O erro aparente "e" é a diferença entre as observações de uma grandeza e seu valor mais provável. Neste caso, o valor mais provável é a média ponderada.

$$
e_{i}=x_{i}-\bar{x}_{P}
$$

Onde,

$$
\begin{aligned}
& \mathrm{e}_{\mathrm{i}}=\text { erro aparente de cada parâmetro; } \\
& \mathrm{x}_{\mathrm{i}}=\text { observação; } \\
& \overline{\mathrm{x}}_{\mathrm{p}}=\text { média ponderada de cada série de } \\
& \text { observações nos pontos; }
\end{aligned}
$$

Os resíduos mostram a diferença entre a média ponderada das observações em cada ponto e os parâmetros $\mathrm{E}, \mathrm{N}$ e $\mathrm{Z}$ isoladamente, ou seja, mostra a diferença para mais o para menos nos eixos $\mathrm{X}$ e Y sobre um ponto de vista planimétrico e uma diferença para mais ou para menos no eixo $Z$ sobre um ponto de vista altimétrico, diferença esta relacionada com a média ponderada das repetições em um único ponto em função do número de satélites e da precisão registrada pelo receptor no momento da medição.

$\mathrm{O}$ índice de precisão mais utilizado é o desvio padrão ou erro médio quadrático (Comastri, 1979). Uma vez calculados os resíduos, o desvio padrão é dado pela equação 4 abaixo:

$$
\sigma=\sqrt{\frac{\sum_{i=1}^{n} e_{i}^{2} \cdot P_{i}}{n-1}}
$$


Onde,

$\sigma=$ desvio padrão;

$e_{i}=$ erro aparente de cada parâmetro;

$\mathrm{P}_{\mathrm{i}}=$ peso de cada observação;

$\mathrm{n}$ = número de repetições em cada ponto;

A partir da equação 4 é possível calcular o desvio padrão da média, que é dado por:

$\sigma_{\overline{\mathrm{x}}_{\mathrm{P}}}=\frac{\sigma}{\sqrt{\sum_{\mathrm{i}=1}^{\mathrm{n}} \mathrm{P}_{\mathrm{i}}}}$

Onde,

$\sigma_{\bar{x}_{P}}=$ desvio padrão da média;

$\sigma=$ desvio padrão das séries de observações;

$\mathrm{P}_{\mathrm{i}}=$ peso de cada observação;

\section{RESULTADOS E DISCUSSÃO}

Os valores mais prováveis requerem o desvio padrão da média, relativo ao método estatístico utilizado, ou seja, as coordenadas (parâmetros E, N e Z) mais prováveis para cada série de 6 repetições nos 4 pontos serão as médias ponderadas mais ou menos desvio padrão da média, Tabela 3 a seguir.

TABELA 3. Tabela dos valores mais prováveis em função da precisão fornecida pelo receptor e do número de satélites.

\begin{tabular}{|c|c|c|c|c|}
\hline \multirow[t]{2}{*}{ Pontos } & \multirow[t]{2}{*}{ Séries } & \multicolumn{3}{|c|}{$\begin{array}{l}\text { VALOR MAIS PROVÁVEL } \\
\qquad \overline{\mathrm{x}}_{\mathrm{P}} \pm \sigma_{\overline{\mathrm{x}}_{\mathrm{P}}}\end{array}$} \\
\hline & & E (m) & $\mathbf{N}(\mathbf{m})$ & $\mathbf{Z}(\mathrm{m})$ \\
\hline \multirow{6}{*}{$\mathrm{P} 1$} & Thi2 & \multirow{6}{*}{$\begin{array}{c}363.109,385 \\
\pm 0,392 \mathrm{~m}\end{array}$} & \multirow{6}{*}{$\begin{array}{c}7.531 .203,292 \\
\quad \pm 0,479 \mathrm{~m}\end{array}$} & \multirow{6}{*}{$\begin{array}{c}888,898 \\
\pm 2,240 \mathrm{~m}\end{array}$} \\
\hline & Thi10 & & & \\
\hline & Thi18 & & & \\
\hline & Thi26 & & & \\
\hline & Thi34 & & & \\
\hline & Thi42 & & & \\
\hline
\end{tabular}

\begin{tabular}{|c|c|c|c|c|}
\hline \multirow{6}{*}{ P2 } & Thi3 & \multirow{6}{*}{$\begin{array}{c}363.399,734 \\
\pm 0,168 \mathrm{~m}\end{array}$} & \multirow{6}{*}{$\begin{array}{c}7.531 .145,128 \\
\quad \pm 0,589 \mathrm{~m}\end{array}$} & \multirow{6}{*}{$\begin{array}{c}899,272 \\
\pm 1,780 \mathrm{~m}\end{array}$} \\
\hline & Thi11 & & & \\
\hline & Thi19 & & & \\
\hline & Thi27 & & & \\
\hline & Thi35 & & & \\
\hline & Thi43 & & & \\
\hline \multirow{6}{*}{ P3 } & Thi4 & \multirow{6}{*}{$\begin{array}{c}363.454,584 \\
\pm 0,630 \mathrm{~m}\end{array}$} & \multirow{6}{*}{$\begin{array}{c}7.531 .342,962 \\
\quad \pm 0,674 \mathrm{~m}\end{array}$} & \multirow{6}{*}{$\begin{array}{c}879,325 \\
\pm 1,775 \mathrm{~m}\end{array}$} \\
\hline & Thi12 & & & \\
\hline & Thi20 & & & \\
\hline & Thi28 & & & \\
\hline & Thi36 & & & \\
\hline & Thi44 & & & \\
\hline \multirow{6}{*}{ P4 } & Thi8 & \multirow{6}{*}{$\begin{array}{c}363.169,843 \\
\pm 1,214 \mathrm{~m}\end{array}$} & \multirow{6}{*}{$\begin{array}{c}7.531 .439,846 \\
\pm 0,361 \mathrm{~m}\end{array}$} & \multirow{6}{*}{$\begin{array}{c}871,354 \\
\pm 0,987 \mathrm{~m}\end{array}$} \\
\hline & Thi16 & & & \\
\hline & Thi24 & & & \\
\hline & Thi32 & & & \\
\hline & Thi40 & & & \\
\hline & Thi48 & & & \\
\hline
\end{tabular}

A Figura 2, abaixo, mostra uma comparação planimétrica entre o posicionamento com antena receptora GPS de precisão (levantamento de referência, coordenadas reais) posicionamento com receptorGPS denavegaçãc e média das repetições de posicionamentos com o receptor GPS de navegação.

Analisando a Figura 2, percebe-se quє a alta variabilidade dos posicionamentos com receptor GPS denavegação, sendo inadmissíve] sua utilização em determinações de pontos de apoio para levantamentos topográficos ou levantamentos geodésicos.

Analisando a alta variabilidade das coordenadas obtidas para um mesmo pontc percebe-se que a média ponderada é condizente com a precisão fornecida pelo fabricante dc receptor, entretanto, não há garantia alguma $d \epsilon$ que tal precisão permaneça inalterável 100\% do tempo.

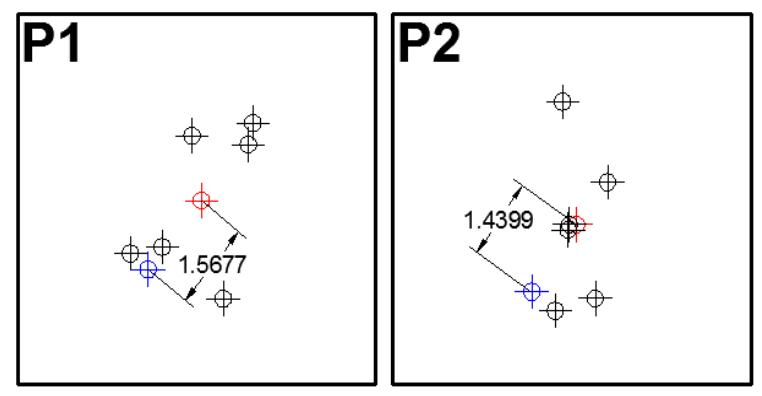




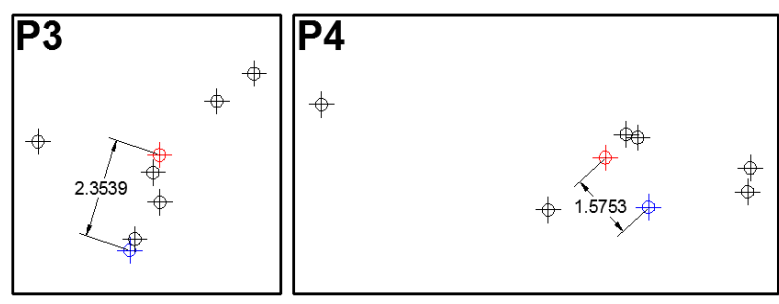

FIGURA 2. Comparação planimétrica entre o posicionamento com receptor GPS de navegação e o valor mais provável encontrado pelo método estatístico. Os pontos em vermelho representam o valor mais provável mais ou menos o desvio padrão da média em cada ponto, conforme Tabela 3. Os pontos em azul representam o levantamento de referência com antena receptora GPS de precisão. A diferença planimétrica entre valor mais provável e ponto levantado com GPS de precisão encontra-se na unidade métrica.

Uma vez determinadas as médias ponderadas foi possível a comparação entre áreas e perímetros. Para tanto, utilizando-se de um levantamento geodésico de precisão com uma antena receptora da Leica $900 \mathrm{C} / \mathrm{S}$, tido como levantamento de referência.

Adiferençaencontradaéinadmissível para levantamentos topográficos ou geodésicos.

Tabela 4. Áreas e perímetros.

\begin{tabular}{|c|c|c|c|}
\hline Repetições & Pontos & ÁREA $\left(m^{2}\right)$ & PERÍMETRO ( m ) \\
\hline \multirow{4}{*}{1} & Thi01 & \multirow{4}{*}{$66.371,753$} & \multirow{4}{*}{$1.041,019$} \\
\hline & Thi02 & & \\
\hline & Thi03 & & \\
\hline & Thi04 & & \\
\hline \multirow{4}{*}{2} & Thi05 & \multirow{4}{*}{$66.410,071$} & \multirow{4}{*}{$1.042,038$} \\
\hline & Thi06 & & \\
\hline & Thi07 & & \\
\hline & Thi08 & & \\
\hline \multirow{4}{*}{3} & Thi09 & \multirow{4}{*}{$67.115,591$} & \multirow{4}{*}{$1.047,990$} \\
\hline & Thi10 & & \\
\hline & Thi11 & & \\
\hline & Thi12 & & \\
\hline \multirow{4}{*}{4} & Thi13 & \multirow{4}{*}{$66.831,946$} & \multirow{4}{*}{$1.046,001$} \\
\hline & Thi14 & & \\
\hline & Thi15 & & \\
\hline & Thi16 & & \\
\hline \multirow{4}{*}{5} & Thi17 & \multirow{4}{*}{$67.433,894$} & \multirow{4}{*}{$1.051,700$} \\
\hline & Thi18 & & \\
\hline & Thi19 & & \\
\hline & Thi20 & & \\
\hline \multirow{4}{*}{6} & Thi21 & \multirow{4}{*}{$67.361,310$} & \multirow{4}{*}{$1.049,538$} \\
\hline & Thi22 & & \\
\hline & Thi23 & & \\
\hline & Thi24 & & \\
\hline \multicolumn{2}{|c|}{ MÉDIA* } & $66.922,617$ & $1.046,344$ \\
\hline \multicolumn{2}{|c|}{ LEV. REF.** } & $66.716,637$ & $1.044,734$ \\
\hline
\end{tabular}

*Valores gerados a partir das médias ponderadas encontradas. **Valores gerados a partir das coordenadas do levantamento de precisão.

\section{CONCLUSÃO}

É inaceitável que alguns profissionais estejam utilizando este tipo de receptor para o posicionamento de pontos que requerem uma qualidade mínima de $50 \mathrm{~cm}$ para georreferenciamento, por exemplo, uma vez que a variabilidade das observações é alta, em função do número de satélites, da baixa precisão do aparelho receptor e outros fatores como os citados na seção 2 .

Analisando a Figura 2, percebe-se que os valores mais prováveis das observações, utilizandose do método estatístico da média ponderada, não satisfazem a prioridade de exatidão mínima exigida em levantamentos de agrimensura, visto que o receptor GPS de navegação não permite uma precisão compatível com a exigida. Isto se evidencia pela comparação planimétrica com levantamento geodésico de precisão (levantamento de referência). Isto é, independente do número de repetições. Os valores obtidos mantêm-se a uma distância não aceitável da real. Entretanto, as coordenadas encontradas pelo método estatístico comprovam a precisão fornecida pelo fabricante do receptor da ordem de 2 metros.

É necessário que haja maior fiscalização e atenção nos trabalhos de georreferenciamento e outros mais que têm sido praticados na ilegalidade por diversos profissionais equivocados.

\section{BIBLIOGRAFIA}

COMASTRI, José Aníbal; FERRAZ, Antônio Santana. Erros nas medições topográficas. Viçosa/MG: Imprensa Universitária da UFV, 1979.

MONICO, João Francisco Galera. Posicionamento pelo NAVSTAR-GPS: descrição, fundamentos e aplicações. São Paulo/SP: Ed. da UNESP, 2007. Vol. 2.

SEGANTINE, Paulo Cesar Lima. GPS: Sistema de posicionamento global. São Carlos/SP: EESC, 2005.

SILVA, Antonio Simões. Ajustamento de observações por mínimos quadrados: aplicações geodésicas. Viçosa/MG: Imprensa Universitária da UFV, 2006. 